\title{
TRACHEA AND GESOPHAGUS.
}

Pierre-Nadal, L. (Bordeaux), - Contribution to the Study of the Physiology of the Esophagus. "Revue Hebd. de Laryngol., d'Otol. et de Rhinol.," January 30, 1909.

The question discussed is whether the lumen of the middle two thirds of the cesophagus is virtual or actual during repose. The conclusion is that in the normal subject, and in a state of repose, the lumen is entirely virtual.

Chichele Nourse.

Hirschland, L. (Wiesbaden).- Tro Cases Illustrating the Importance of the Direct Methods of Examination. "Zeitschrift für Iaryngol.," vol. ii, Part IV.

In the first case, that of a chill, aged three, the symptoms were such as to suggest the possibility of a foreign body in the bronchus. Examination, however, with the bronchoscope through a low tracheotomy opening proved the condition to be that of rupture of a diseased bronchial gland into the right main bronchus. Recovery took place.

In the second case it was found possible by means of the direct methods to arrive at an accurate diagnosis in an obscure case in which an osophageal abscess with rupture into the trachea had followed a burn by caustic soda.

Thomas Guthrie.

\section{EAR.}

Schoetz, W. (Heidelberg).-Epidermic Cysts following Transplantation in the Carity produced by the Radical Mastoid Operation. "Arch. of Otol.," December, 1908.

In one case the cyst formed a swelling extending from the tip of the mastoid into the retro-mandibular fossa. The auther thinks a portion of the plastic skin-flap may have been shut in under the Thiersch graft.

Dundas Grant.

Pistre, E. (Bordeaux).-Pure Fibroma "f the Auricle (Anti-helix). "Revue Hebd. de Larrngol. d'Otol. et de Rhinol.," March 13, 1909 .

The growth of the tumour followed a priek with a thorn of the Cassia occidentalis. Five days later a small growth appeared, which in ten dass attained the size of a large cherry, attarched by a small pedicle. The tumour was solid and quite spherical, very tough, and crealing under the knife. The section was yellowish-white, composed of numerous concentric fibres.

Chichele Nourse.

Zebrowski, A.--A Case of Double-sided Mastriditis after Tranmatir Perforation of the Drum Membranes. Quoted from "Gazeta leliarska," 1909, No. 4 ; “'St. Petersburger med. Woeh.," xxxiv, 1909, S. 190.

The case is of interest owing to the rarity of complications which require operation occurring after traumatic rupture of the membrane. The pratient, a soldier, was brought to hospital in an unconscious condition caused by a bomb explosion in Warsaw. The unconsciousness lasted some days. Thirteen days after the operation bilateral otorrhera developed, and on examination a perforation was found in each membrane in the anterior inferior quadrant. The hearing was greatly impaired. 